\title{
Strength of Binary and Ternary Blended Cement Pastes Containing Palm Oil Fuel Ash and Metakaolin Exposed To Sodium Sulphate
}

\author{
Mohd Hanif Ismail ${ }^{1, *}$, Nor Hazurina Othman ${ }^{1}$ Ahmad Zurisman Mohd Ali ${ }^{1}$, Megat Azmi \\ Megat Johari ${ }^{2}$, and Kamar Shah Ariffin ${ }^{3}$ \\ ${ }^{1}$ Faculty of Civil and Environmental Engineering, Universiti Tun Hussein Onn Malaysia, 86400, \\ Johor, Malaysia \\ ${ }^{2}$ School of Civil Engineering, Universiti Sains Malaysia, 11800, Pulau Pinang, Malaysia \\ ${ }^{3}$ School of Materials and Mineral Resources Engineering, Universiti Sains Malaysia, 11800, Pulau \\ Pinang, Malaysia
}

\begin{abstract}
The compressive strength of binary (BBCP) and ternary blended cement pastes (TBCP) containing Palm Oil Fuel Ash (POFA) and Metakaolin (MK) exposed to $3 \%$ sodium sulphate solution has been studied. The ordinary Portland cement (OPC) was partially replaced with POFA and MK on mass-for-mass basis. All specimens were first cured for 28 days in normal water and subsequently subjected to full immersion in sodium sulphate solution for 150 days for the compressive strength evaluation. The results show that partial replacement of cement with POFA and MK improved the durability of the cement pastes by reducing the damage caused by sulphate attack.
\end{abstract}

\section{Introduction}

By using recycled materials in concrete as a filler or additive, it was found that the mechanical properties of the concrete can be improved [1-3]. Furthermore, the use of recycled materials in concrete can reduce environmental pollution and promote recycling in the industry. POFA use as a cement replacement material is an effort to control the pollution of the environment by reducing the use of cement in the construction industry. The use of POFA and MK as pozzolanic material by partially replacing cement has been shown to improve the durability of cement paste, mortar and concrete [4-7]. POFA contains high proportion of silica while MK possesses high content of alumina, hence the utilization of POFA and MK will affect the durability of cement paste, mortar and concrete. This paper will discuss the changes of compressive strength of OPC, BBCP and TBCP containing POFA and MK exposed to $3 \%$ sodium sulphate solution. In addition, the changes in the intensity of calcium hydroxide $(\mathrm{CH})$, calcium silicate hydrate $(\mathrm{C}-\mathrm{S}-\mathrm{H})$ and ettringite (ETT) will also be discussed. The changes in the intensity of this mineral are

* Corresponding author: mohdhanif@uthm.edu.my 
correlated to the changes in the compressive strength of OPC paste as well as the BBCP and TBCP pastes containing POFA and MK.

\section{Experiment}

\subsection{Materials preparation}

The ordinary Portland cement was partially replaced by POFA and MK at the rates of $0 \%$, $20 \%$ and $40 \%$ by mass of total binder. The POFA was treated via heat treatment and ground to a median particle size of approximately $9 \mu \mathrm{m}$. While, the Kaolin was turned into Metakaolin also via heat treatment and ground to a median particle size of approximately 8 $\mu \mathrm{m}$. The water binder $(\mathrm{w} / \mathrm{b})$ ratio was kept constant at 0.3 for all mixtures. The proportions of the cement pastes are shown in Table 1. All specimens were removed from their respective moulds 24 hours after casting and cured in water maintained at room temperature for 28 days. Then, all specimens were subjected to full immersion in $3 \%$ sodium sulphate solution up to age of 180 days.

Table 1. Mix proportions of cement paste and pastes containing POFA and MK

\begin{tabular}{|l|l|l|l|l|}
\hline Mix & OPC (\%) & POFA (\%) & MK (\%) & w/b \\
\hline OPC & 100 & - & - & 0.3 \\
\hline M5 & 95 & - & 5 & 0.3 \\
\hline M10 & 90 & - & 10 & 0.3 \\
\hline P20 & 80 & 20 & - & 0.3 \\
\hline P40 & 60 & 40 & - & 0.3 \\
\hline P15M5 & 80 & 15 & 5 & 0.3 \\
\hline P35M5 & 60 & 35 & 5 & 0.3 \\
\hline P10M10 & 80 & 10 & 10 & 0.3 \\
\hline P30M10 & 60 & 30 & 10 & 0.3 \\
\hline
\end{tabular}

\subsection{Compressive strength test}

The compressive strength of the hardened cement paste cubes was determined using a 3000 $\mathrm{kN}$ automatic compression machine. The test was performed on average of five number of samples of $50 \times 50 \times 50 \mathrm{~mm}$ cement paste cubes at the ages of 60, 90 and 180 days according to ASTM C109.

\subsection{X-Ray Diffraction (XRD) analysis}

The X-ray scans were performed for 2 theta between $5^{\circ}$ and $90^{\circ}$ at 60,90 and 180 days on crushed pastes sample in powder form using X-ray diffraction (XRD) Advance Bruker DX8 equipment according to BS EN 13925-1:2003. The collected X-ray scans recorded as intensity in unit counts.

Then, the quantitative intensity changes of $\mathrm{C}-\mathrm{S}-\mathrm{H}, \mathrm{CH}$ and ETT in the OPC, BBCP and TBCP were observed using XRD analyzer via X'Pert Highscore Plus software via Refinement Method on each testing age. All the XRD data from the X'Pert Highscore Plus software was further analyzed using Microsoft Excel. 


\section{Results and discussion}

\subsection{Changes of compressive strength}

The compressive strength of cement pastes exposed to normal water and $3 \%$ sodium sulphate solution is given in Table 2 . While the changes of compressive strength of cement pastes exposed to $3 \%$ sodium sulphate solution compared to cement paste exposed to normal water is given in Fig. 1. From those Table and Figure, it shows that the compressive strength of OPC, BBCP and TCBP containing POFA and MK increased when exposed to 3 $\%$ sodium sulphate solution after 30 (60 days/age) and 60 (90 days/age) days of exposure period but decreased upon a prolonged exposure period of 150 (180 days/age) days.

Table 2. Compressive strength of cement pastes exposed to normal water and $3 \%$ sodium sulphate solution

\begin{tabular}{|l|c|c|c|c|c|c|}
\hline & \multicolumn{3}{|c|}{$\begin{array}{c}\text { normal water } \\
\text { (MPa) }\end{array}$} & \multicolumn{3}{c|}{ 3\% sodium sulphate solution } \\
(MPa)
\end{tabular}

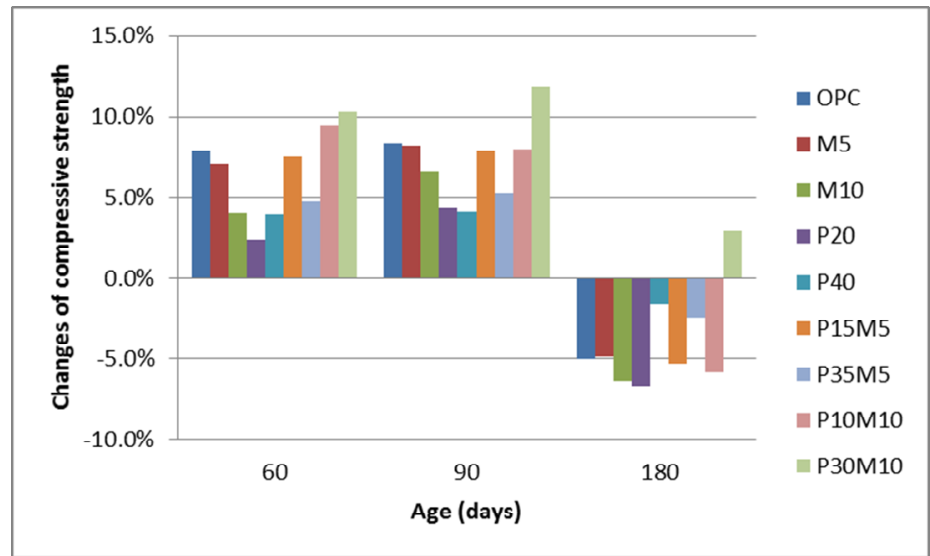

Fig 1. Changes of compressive strength of cement pastes exposed to $3 \%$ sodium sulphate solution compared to cement pastes exposed to normal water. 
The increase of strength of OPC cement paste exposed to $3 \% \mathrm{Na}_{2} \mathrm{SO}_{4}$ solution was influenced by the reaction of sulphate ions with $\mathrm{CH}$ to form gypsum [8,9]. Gypsum formation at the beginning lead to denser structure as a result of precipitation of products within voids and micropores [8-10]. The decrease in strength of the OPC cement paste exposed to $3 \% \mathrm{Na}_{2} \mathrm{SO}_{4}$ solution was affected by the excessive formation of gypsum and ettringite which create internal stress in the cement paste and decrease the $\mathrm{C}-\mathrm{S}-\mathrm{H}$ formation [9].

The increase in strength of the BBCP containing MK was lower than the OPC cement paste but BBCP containing MK has higher durability compared to OPC cement paste for short and long term exposure because the BBCP containing MK has a higher C-S-H content, outcomes of cement hydration and pozzolanic reaction and less formation of gypsum and ettringite than OPC cement paste [11].

It was found that the BBCP containing POFA have higher durability compared to the OPC cement paste and the BBCP containing MK for short and long term exposure. Higher $\mathrm{C}-\mathrm{S}-\mathrm{H}$ contents in the $\mathrm{BBCP}$ containing POFA resulting from hydration and pozzolanic reaction and lower formation of gypsum and ettringite than the OPC cement paste and the $\mathrm{BBCP}$ containing MK makes the BBCP containing POFA more resistant to sulphate with higher strength value [6].

The increase in strength may be attributed to; 1) continuous hydration of unhydrated cement components and additional reaction of POFA and MK to form more C-S-H leading to an increase in compressive strength 2) The reaction of sulphate ions with hydrated cement component to form gypsum and ettringite. These two reactions led to denser structure as a result of precipitation of products within the voids and micropores in the cement pastes $[8,10]$. The compressive strength of cement pastes initially increased, and then began to decrease until the specimens eventually deteriorated after 150 days of exposure. The reaction of sulphate ions with unhydrated cement component to form gypsum and ettringite become more dominant leading to formation of internal stress and microcracks and this decreases the strength $[8,10]$.

\subsection{Losses of $\mathrm{CH}, \mathrm{C}-\mathrm{S}-\mathrm{H}$ and changes of ettringite intensity}

The losses of $\mathrm{CH}$ and C-S-H intensity of cement pastes exposed to 3\% sodium sulphate soluiton compared to cement pastes exposed to normal water is shown in Fig. 2. Meanwhile Fig. 3 shows the changes of ettringite intensity of cement pastes exposed to $3 \%$ sodium sulphate solution compared to cement pastes exposed to normal water.

After being exposed to sodium sulphate solution for 150 days, the P30M10 cement paste shows the highest losses or reduction of $\mathrm{CH}$ intensity while, the OPC cement paste shows the lowest reduction of $\mathrm{CH}$ intensity after being exposed to sodium sulphate solution for 150 days. The reduction of $\mathrm{CH}$ intensity was due to 1) pozzolanic reaction; $\mathrm{CH}$ reacts with silica and alumina to form C-S-H 2) the formation of ettringite; $\mathrm{CH}$ reacts with sulphate ions to form gypsum then, gypsum reacts with $\mathrm{C}_{3} \mathrm{~A}, \mathrm{CAH}$ and $\mathrm{CSAH}$ to form ettringite thus reduces the calcium content in the cement paste. The reduction of $\mathrm{CH}$ in the cement paste exposed to sulphate solution weakens the strength of the cement pastes [9].

When compared to the cement pastes exposed to normal water, the reduction in C-S-H intensity of the cement pastes exposed to sodium sulphate solution increased after 30, 60 and 150 days of exposure.

The count of C-S-H for each specimens is declining after both samples were exposed to $3 \%$ sodium sulphate solution. The OPC cement paste shows the highest losses of C-S-H intensity, meanwhile the P30M10 shows the lowest reduction of C-S-H intensity after 150 days of sulphate solution exposure. 

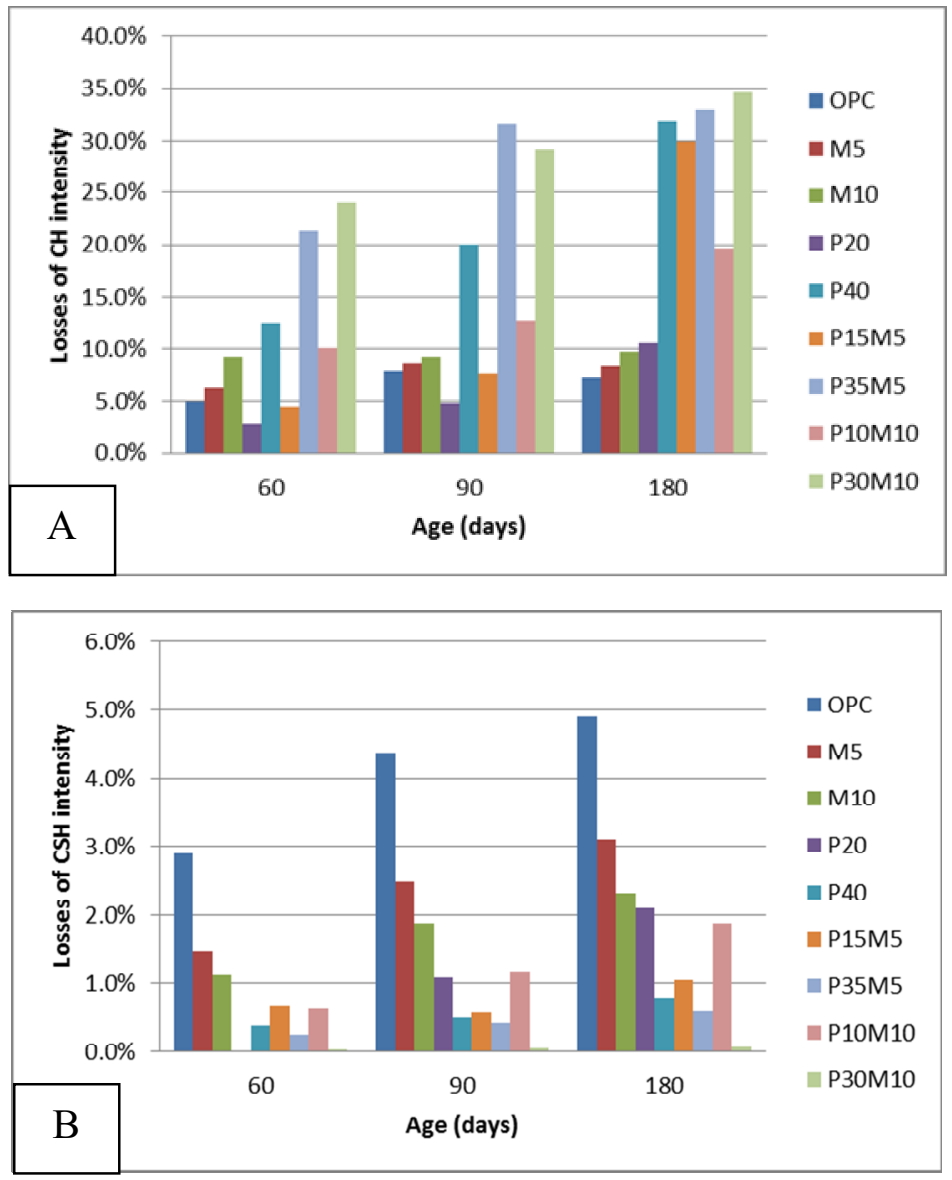

Fig 2. Losses of $\mathrm{CH}$ (A) and C-S-H (B) intensity of cement pastes exposed to $3 \%$ sodium sulphate solution compared to cement pastes exposed to normal water.

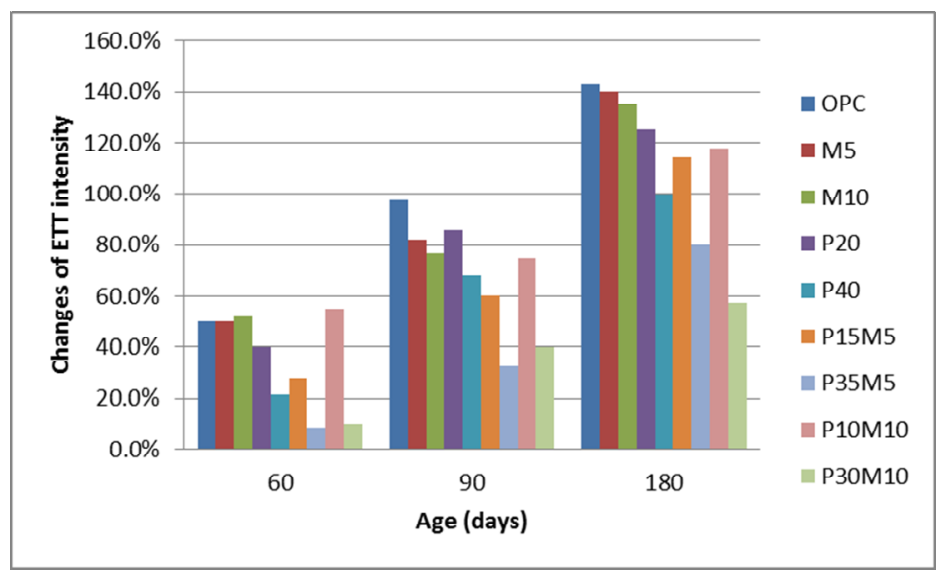

Fig 3. Changes of ettringite intensity of cement pastes exposed to $3 \%$ sodium sulphate solution compared to cement pastes exposed to normal water. 
The reduction of $\mathrm{C}-\mathrm{S}-\mathrm{H}$ intensity was due to 1) $\mathrm{CH}$ reacts with sulphate ions to form gypsum; a reduction of $\mathrm{CH}$ contents causes a reduction in the formation of $\mathrm{C}-\mathrm{S}-\mathrm{H} 2$ 2) formation of ettringite; gypsum reacts with $\mathrm{C}_{3} \mathrm{~A}, \mathrm{CAH}$ and $\mathrm{CSAH}$ to form ettringite reduces the calcium contents in cement paste, the reduction of the calcium also leads to reduction of C-S-H contents.

From Fig. 3, the OPC cement paste shows the highest increase in ettringite intensity meanwhile the P30M10 cement paste shows the lowest increase in ettringite intensity after 150 days of exposure. The increased ettringite intensity in cement pastes was due to the presence of sulphate ions in sodium sulphate solution. The calcium hydroxide $(\mathrm{CH})$ reacts with sulphate ion to form gypsum and gypsum reacts with $\mathrm{C}_{3} \mathrm{~A}, \mathrm{CAH}$ and $\mathrm{CSAH}$ to form more ettringite. The losses of C-S-H in OPC and P30M10 cement paste can be seen in Fig. 4 and Fig. 5.

The P30M10 cement paste exhibited the highest reduction losses in $\mathrm{CH}$ content in sulphate solution, but portrayed a much higher durability compared to the other cement pastes based on the test results in Fig. 1. The P30M10 underwent high formation of C-S-H which contributed to the strength of the P30M10 cement paste. The P30M10 cement paste also recorded the lowest formation of ettringite which also contributed to higher durability performance compared to other cement paste.

The OPC cement paste showed the highest $\mathrm{CH}$ content compared to the other cement pastes and suffered a reduction of strength, moreover the OPC cement paste demonstrated lower durability against sulphate attack. High $\mathrm{CH}$ contents of the OPC cement paste caused high formation of gypsum and ettringite thus promoting deterioration to the OPC cement paste after 150 days of exposure to sodium sulphate.
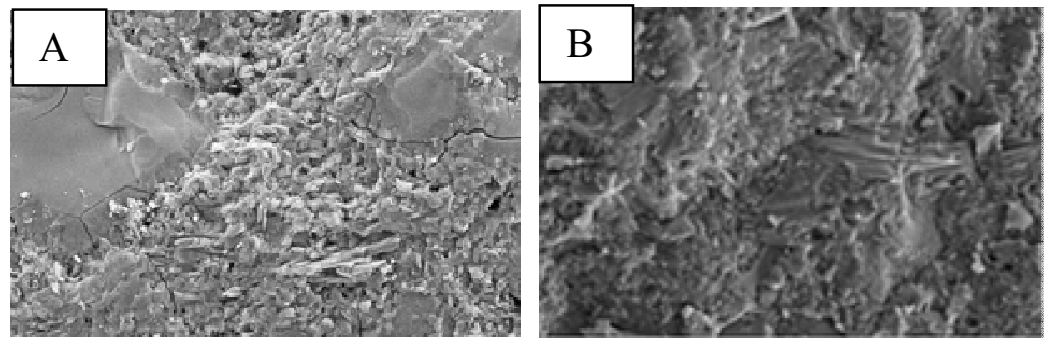

Fig 4. OPC cement paste before (A) and after (B) exposure to $3 \%$ sodium sulphate solution.
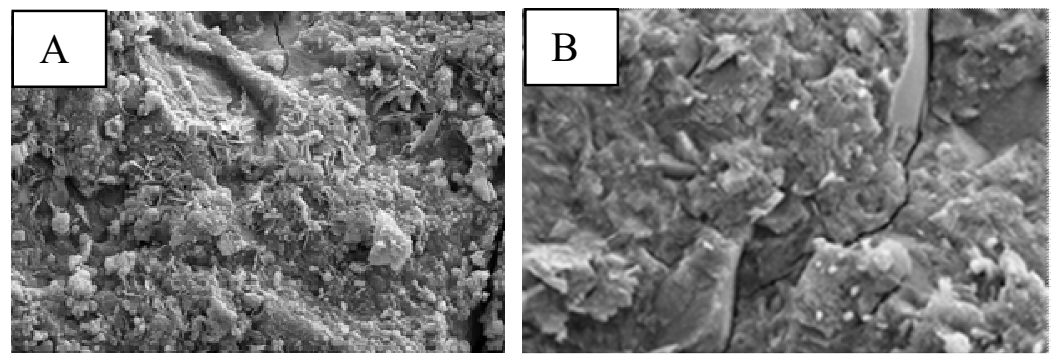

Fig 5. P30M10 cement paste before (A) and after (B) exposure to 3\% sodium sulphate solution.

Overall, high of C-S-H contents contributes to high strength properties and high durability against sulphate attack. The losses of C-S-H contents in the cement paste cause by the formation of gypsum and ettringite which result in high formation of internal stress in the cement paste thus deteriorate the cement paste and reduces the strength of the cement paste. The use of pozzolan lowers the $\mathrm{CH}$ content and increases the $\mathrm{C}-\mathrm{S}-\mathrm{H}$ in the cement 
paste thus reduces the formation of gypsum and ettringite in the cement paste and increases the durability of the cement paste when exposed to sulphate solution.

\section{Conclusions}

The C-S-H content in the TBCP containing POFA and MK was higher than the OPC cement paste and the $\mathrm{BBCP}$ containing POFA and $\mathrm{MK}$ resulting from cement hydration and pozzolanic reaction and lower formation of gypsum and ettringite. As a result, the TBCP containing POFA and MK is more durable than the OPC cement paste and the BBCP containing POFA and MK with the higher strength. Furthermore, the P30M10 cement paste is the best and the most suitable cement paste for sulphate environment with the highest resistence against sulphate attack compared to the other tested specimens.

The authors gratefully acknowledge the Universiti Sains Malaysia for providing the needed support including financial support through the Research University (1001/PAWAM/814191) Grant Scheme for undertaking the research work.

\section{References}

[1] S.K. Faisal, J.M. Irwan, N. Othman, M.H. Wan Ibrahim, Flexural toughness of ringshaped waste bottle fibre concrete, MATEC Web of Conference, 47, 01002, (2016)

[2] S.K. Faisal, J.M. Irwan, N. Othman, W. Ibrahim, R.M Asyraf, M.M.K. Annas, Performance of concrete using light waste PET fibre, Advance Materials Research, 795, 352-355, (2014)

[3] J.M. Irwan, M.M.K Annas, A.K. Aeslina, R.M. Asyraf, S.K. Faisal, Cracking propagation of reinforced concrete using polyethylene terephtalate (PET) bottles as fine aggregate, Advanced Materials Research, 911, 474-478, (2014)

[4] J.J. Brooks and M.A. Megat Johari, Effect of metakaolin on creep and shrinkage of concrete, Cement Concrete Composition, 23, 495-502, (2001)

[5] H.S. Kim, S.H. Lee and H.Y Moon, Strength properties and durability aspects of high strength concrete using Korean metakaolin, Construction and Building Materials, 21, 1229-1237, (2007)

[6] W. Kroehong, T. Sinsiri, C. Jaturapitakkul, P. Chindaprasirt, Effect of palm oil fuel ash fineness on the microstructure of blended cement paste, Construction and Building Materials, 25, 4095-4104, (2011)

[7] M.A. Megat Johari,A.M. Zeyad, N. Muhamad Bunnori and K.S. Ariffin, Engineering and transport properties of high-strength green concrete containing high volume of ultrafine palm oil fuel ash, Construction and Building Materials, 30, 281-288, (2012)

[8] E.E. Hekal, E. Kishar, and H. Mostafa, Magnesium sulphate attack on hardened blended cement pastes under different circumstances, Cement Concrete Research, 32, 1421-1427, (2002)

[9] M.S. Hasan, Prediciting life expectancy of concrete septic tanks exposed to sulphate and biogenic sulphuric acid attack, Master Thesis, RMIT University, Australia, (2009)

[10]P.J. Ramadhansyah, Properties of concrete containing rice husk ash under aggressive environments subjected to wetting and drying, $\mathrm{PhD}$ Thesis, Universiti Sains Malaysia, Malaysia, (2012)

[11]A.A. Ramezanianpour and H. Bahrami Jovein, Influence of metakaolin as supplementary cementing material on strength and durability of concretes, Construction and Building materials, 30, 470-479, (2012)

[12] S.M.A. El-Gamal, M.S. Amin and M. Ramadan, Hydration characteristic and compressive strength of hardened cement paste containing nano-metakaolin, Housing 
and Building National Research Centre, accepted on 4 November 2014 http://ees.elsevier.com/hbrcj

[13] M.W. Hussin and A.S.M.A. Awal, Palm oil fuel ash-a potential pozzolanic material in concrete construction, Int. Conference on Urban Engineering in Asian Cities in the $21^{\text {st }}$ Century, Bangkok, Thailand, (1996)

[14]C. Jaturapitakkul, K. Kiattikomol, W. Tangchirapat and T. Saeting, Evaluation of the sulphate resistance of concrete containing palm oil fuel ash, Construction Building Materials, 21(7), 1399-405, (2007)

[15]J.M. Khatib and S. Wild, Pore size distribution of metakaolin paste, Cement Concrete Research. 26(10),1545-1553, (1996)

[16]P.K. Mehta, Concrete: Structure, properties and materials, Prentice-Hall International New Jersey, USA, (1986)

[17]M.A. Megat Johari, J.J. Brooks, Shahid Kabir and Patrice Rivard, Influence of supplementary cementitious materials on engineering properties of high strength concrete, Construction and Building Materials, 25, 2639-2648, (2011) 